\title{
Treatment of constipation in older people
}

\author{
Dov Gandell MDCM, Sharon E. Straus MD MSc, Maria Bundookwala MD, Vincent Tsui MD, \\ Shabbir M.H. Alibhai MD MSc
}

$\mathrm{T}$ he prevalence of constipation rises dramatically with age, with some estimates approaching $50 \%$ among adults over 80 years of age. ${ }^{1} \mathrm{Up}$ to $40 \%$ of seniors living in the community and $60 \%$ of those in institutions are affected. ${ }^{2,3}$ Lower socioeconomic class, nonwhite race, regular medication use, female sex, and symptoms of anxiety and depression have all been associated with increased prevalence of constipation among older people. ${ }^{4,5}$

Consequences of constipation can be substantial. In susceptible older people who are frail, excessive straining can trigger a syncopal episode, or coronary or cerebral ischemia. ${ }^{6}$ Less acutely, constipation leading to fecal impaction can present with anorexia, nausea and pain associated with functional decline. ${ }^{7}$ Case reports have identified stercoral ulceration, perforation and death as consequences of fecal impaction. ${ }^{8}$ Quality of life also appears to be lower for older people with than without constipation, and longterm care facilities incur high costs managing the problem, estimated at US\$2253 per year per resident. ${ }^{9}$

Given the growing proportion of older adults in North America, effective management of constipation by health care professionals will be increasingly necessary. Randomized controlled trials (RCTs), mostly categorized as lower quality with some higher quality trials, exist for the treatment of constipation in older people. New agents, with different mechanisms of action, have been developed. In this article, we review the efficacy and safety of treatments for constipation in older people. A summary of the evidence used in this review is found in Box 1.

\section{How is constipation defined?}

Any complaint of difficulty passing stool, incomplete passage of stool or diminished frequency identifies the problem. Straining is the most commonly identified symptom by older adults, even though physicians tend to rely on bowel movement frequency to diagnose constipation..$^{10}$ Additionally, patients tend to underestimate their frequency of bowel movements. ${ }^{11}$ Normal stool frequency can vary between 3 motions per day and 3 motions per week. Frequencies outside that range may also be normal if a change from baseline has not been observed and no other symptoms manifest. For patients with moderate to severe cognitive impairment, diagnosis usually depends on a caregiver's report.

In research settings, the consensus-based Rome III criteria (Box 2) are frequently used to define chronic constipation and can be used to further characterize the problem in the clinical setting. ${ }^{12}$

\section{What causes constipation in older people?}

The causes of primary, or idiopathic, chronic constipation, including the subtypes of normal transit, slow transit and dyssynergic defecation (i.e., related to neuromuscular dysfunction), remain unknown. Despite the aging colon displaying smaller and more tightly packed collagen fibres as well as a reduced number of myenteric plexus neurons, age-related changes in colonic anatomy and physiology are not considered to be major contributors to the development of constipation. ${ }^{13}$ Decreased mobility, low fibre intake and limited fluid intake have also been implied as causes of constipation, but there is little evidence from the literature to support these claims.

Secondary causes of constipation are more easily identified. Medications, metabolic abnormalities and disease states are common culprits and often coexist in older people. These causes
Competing interests: None declared.

This article has been peer reviewed.

Correspondence to: Dov Gandell, dov. gandell@sunnybrook.ca

CMAJ 2013. DOI:10.1503 /cmaj.120819

\section{KEY POINTS}

- The prevalence of constipation increases dramatically with age, affecting almost 1 in 2 adults over 80 years of age.

- In older people, the predominant symptom of constipation is more frequently straining than decreased stool frequency.

- Randomized controlled trials support the use of osmotic agents (polyethylene glycol and lactulose) to treat symptoms of constipation in older people.

- Evidence supporting the use of bulk agents, stool softeners, stimulants and prokinetic agents is lacking, limited or inconsistent. 
should be identified and treated before applying a label of primary constipation. Opioid analgesics, calcium-channel blockers, oral iron supplements and antidiarrheal agents are frequently used medications that have constipation as an adverse effect. Disease states such as hypothyroidism, hypercalcemia, stroke, Parkinson disease and colorectal carcinoma can cause symptoms of constipation in older people. Boxes 3 and 4 list medications and disease states commonly implicated in causing constipation. ${ }^{14}$

\section{Are investigations required?}

Evidence-based recommendations for the diagnostic work-up of chronic constipation in older

\section{Box 1: Evidence used in this review}

To identify relevant randomized controlled trials, we searched each of the following databases from the earliest available date through Jan. 6, 2012: MEDLINE (1966), Embase (1980) and CINAHL (1982). We used the search term "constipation" combined with floating subheadings for all possible therapies. Constipation was also combined with the following terms: "osmotic laxative," "irritant laxative," "bulk laxative," "fecal softener," "lactulose," "sorbitol," "magnesium sulfate," "senna," "bisacodyl," "danthron," "cascara," "psyllium," "methylcellulose," "calcium polycarbophil," "isphagula," "bran," "celandine," "plantain," "alovera," "docusate," "poloxalkol," "mineral oil," "glycerine," "misoprostol," "erythromycin," "herbal," "traditional," "colchicine," "Chinese herbal," "milk of magnesia" and "polyethylene glycol." We searched reference lists of previous reviews and trials on constipation in adults and older people for additional reports.

We included studies if they were randomized controlled studies, had a baseline definition of constipation (any definition was eligible) and the study population had a mean or median age of at least 65 years. For the effect of fluid intake and physical activity on constipation, we accepted observational studies, since randomized controlled trials were not found. We excluded studies if they were not published in English, were conducted in palliative or intensive care settings, or the therapy had been withdrawn from the market at the time of the search. Two of us (D.G. and M.B.) independently reviewed titles and abstracts and extracted data in a standardized manner. Data on participant age, treatment, control, study setting, inclusion criteria, exclusion criteria, outcomes and follow-up were extracted. We assessed the quality of included trials. Disagreements were resolved by consensus.

\section{Box 2: Rome III diagnostic criteria* for chronic constipation}

1. Must include 2 or more of the following:

a. Straining during at least $25 \%$ of defecations

b. Lumpy or hard stools in at least $25 \%$ of defecations

c. Sensation of incomplete evacuation for at least $25 \%$ of defecations

d. Sensation of anorectal obstruction/blockage for at least $25 \%$ of defecations

e. Manual manoeuvres to facilitate at least $25 \%$ of defecations (e.g., digital evacuation, support of the pelvic floor)

f. Fewer than 3 defecations per week

2. Loose stools are rarely present without the use of laxatives

3. Insufficient criteria for irritable bowel syndrome

*Criteria fulfilled for the last 3 months with symptom onset at least 6 months before diagnosis.

Reprinted, with permission, from Rome III diagnostic criteria for functional gastrointestinal disorders. ${ }^{12}$ patients cannot be made because of the absence of research addressing the issue. We suggest conducting a thorough history and physical examination to elicit symptoms and signs of secondary causes of constipation. Careful review of medications, with the possibility of reducing the dose or substituting with another medication that does not have constipation as an adverse effect should be considered if the benefits of the drug are not greater than the bowel symptoms. Clinical judgment should be applied when requesting laboratory tests to identify metabolic causes such as hypothyroidism and hypercalcemia. An abdominal radiograph can help to exclude fecal impaction in patients who are immobile or cognitively impaired. If alarm symptoms or signs are present (Box 5), local or national guidelines for colon cancer screening should be consulted.

\section{What treatments are effective?}

Evidence from RCTs supports the use of osmotic agents as an effective treatment of chronic constipation in older people. One RCT evaluating electromyographic biofeedback for dyssynergic defecation also revealed benefit. Evidence supporting the use of bulk agents, stool softeners, stimulants and prokinetic agents was lacking, limited or inconsistent. At the time of our literature search, lifestyle modifications had not been evaluated in RCTs. The evidence is summarized herein by treatment, and details of the supporting trials $^{15-30}$ are summarized in Appendix 1 (available at www.cmaj.ca/lookup/suppl/doi:10.1503 /cmaj.120819/-/DC1).

\section{Oral therapy}

\section{Osmotic agents}

Osmotic agents exert their effect by promoting the secretion of water into the colonic lumen to maintain isotonicity with plasma. Lactulose and polyethylene glycol are commonly used osmotic agents. Studies of salts of poorly absorbed cations and anions, such as magnesium- and phosphate-based agents, did not meet our inclusion criteria.

Four placebo-controlled RCTs of osmotic agents $(n=250)$ all revealed statistically significant results in favour of active treatment. ${ }^{15-18} \mathrm{In}$ one of the trials, polyethylene glycol improved stool frequency and resulted in improvement in Rome III criteria among 57 patients with Parkinson disease who had constipation $(80 \%$ [16/20] in the treatment group v. 30.4\% [7/23] in the placebo group, $95 \%$ confidence interval [CI] $23.9 \%-75.3 \%$ for the difference, $p=$ 
0.0012).$^{18}$ Two trials revealed benefit with lactulose. The first reported that patients given lactulose required less additional laxative use over 3 weeks than those in the placebo group (87\% [47/54] v. $61 \%$ [30/49], $p<0.02) .{ }^{17}$ The second trial, conducted over 12 weeks, reported a higher mean ( \pm standard deviation) stool frequency per day with lactulose than with placebo $(0.63 \pm 0.31$ lactulose v. $0.58 \pm 0.30$ placebo, $p<0.02) .{ }^{15}$ The fourth trial showed that lactitol, another disaccharide similar to lactulose, increased stool frequency over 4 weeks $(p<0.001)$, but no specific point estimate was reported. ${ }^{16}$

Bloating, flatulence, abdominal pain and diarrhea are potential adverse effects from osmotic laxatives. These effects occur most often with lactulose because of its metabolism by colonic bacteria to carboxylic acids. Patients can also develop an aversion to the sweet taste of lactulose. Polyethylene glycol is metabolically inert and can be dissolved in other liquids.

Magnesium- and phosphate-based laxatives carry the risk of excessive absorption resulting in dose-dependent hypermagnesemia or hyperphosphatemia. More caution is advised in patients with renal impairment. ${ }^{31}$

\section{Bulk agents}

Nonabsorbable, soluble dietary fibres, or bulk agents, exert their laxative effect by holding water in stool, thereby increasing stool weight, increasing colonic distension and improving frequency of bowel movements. There are natural, semisynthetic and synthetic varieties. Galacto-oligosaccharide is another nonabsorbable polysaccharide bulk laxative that has been evaluated in RCTs but is not readily available to consumers.

\section{Box 3: Drugs commonly associated with} constipation

Over-the-counter drugs

- Antacids containing calcium or aluminum

- Calcium supplements

- Nonsteroidal anti-inflammatory drugs

- Oral iron supplements

- Antihistamines

Prescription drugs

- Opioids

- Calcium-channel blockers

- Antiparkinsonian agents

- Anticholinergics

- Diuretics

- Antipsychotics

- Tricyclic antidepressants

Source: Gallagher and O'Mahony. ${ }^{14}$
We found 7 RCTs $(n=254)$ in which older people were randomly assigned to receive either dietary fibre or placebo. ${ }^{19-25}$ Two trials evaluating psyllium $(n=20)$ did not show improvements in stool frequency. ${ }^{19,20}$ Results from 3 trials of galacto-oligosaccharide were mixed. Use of a mixture of fibre (guar gum and wheat bran) and the osmotic agent lactitol in yogourt resulted in increased stool frequency $(5.9 \pm 3.8 / \mathrm{wk}$ v. placebo $4.3 \pm 1.8 / \mathrm{wk}, p<0.05)$ in 51 medical and surgical inpatients. ${ }^{21}$ It is unclear from this study whether the bulk agent or the osmotic agent was more responsible for the favourable result.

\section{Box 4: Disease states commonly associated} with constipation
Metabolic
- Diabetes
- Hypothyroidism
- Hypercalcemia
- Hypokalemia
Gastrointestinal
- Colorectal carcinoma
- Diverticulosis
- Stricture
- Hemorrhoids
- Rectal prolapse
Neurologic
- Stroke
- Parkinson disease
- Dementia
- Multiple sclerosis
- Autonomic neuropathy
Psychiatric
- Depression
- Anxiety
- Somatization
Connective tissue
- Systemic sclerosis
- Amyloidosis
Source: Gallagher and O'Mahony. ${ }^{14}$

Box 5: Alarm symptoms and signs in patients with chronic constipation

- Family history of colon cancer

- Hematochezia

- Anemia

- Weight loss $\geq 5 \mathrm{~kg}$ in previous 6 months

- Positive result of fecal occult blood test

- Persistent constipation unresponsive to treatment

- Acute onset of constipation

Source: Brandt et al. ${ }^{39}$ 
Fermentation of natural bulk agents by colonic bacteria can cause bloating and gas. Mechanical obstruction following consumption of bulk agents has been reported..$^{32}$ Nonambulatory patients with low fluid intake may be at increased risk. Rare cases of allergic reactions to psyllium have also been described. ${ }^{31}$

\section{Stimulants}

Stimulants exert their effect by increasing intestinal motility and colonic secretions. Anthranoids (senna, cascara) and diphenylmethane derivatives (bisacodyl) are commonly used stimulants.

Two trials involving patients in nursing homes ( $n=182)$ compared stimulants with placebo and revealed significant benefit. In the first trial, use of an herbal mixture containing senna resulted in 4.14 more bowel movements on average over 4 weeks versus placebo $(p=0.017) .{ }^{26}$ The second trial studied an herbal formulation containing an anthraquinone combined with the osmotic agent magnesium oxide; however, the reported benefit $(5.6 \pm 2.0$ spontaneous bowel movements/wk in the study group v. $4.6 \pm 2.5 / \mathrm{wk}$ in the placebo group; $p=0.049$ ) did not change a global assessment of efficacy by caregivers. ${ }^{27}$ Bisacodyl has not been evaluated in RCTs in older patients.

Abdominal pain, electrolyte imbalances and allergic reactions have been reported as adverse effects of stimulant laxatives. ${ }^{31}$ Regular use of anthranoids can cause pseudomelanosis coli, a benign and often completely reversible pigmentation of the mucosa of the large intestine. No definitive relation to myenteric nerve damage or carcinogenesis has been established with the use of stimulant laxatives. Regular use may lead to decreased efficacy over time. ${ }^{31}$

\section{Stool softeners}

Stool softeners act as anionic surfactants, easing the interaction of water with solid stool. Intestinal motility and colonic secretions may also be increased. Stool softeners are generally well tolerated.

One trial of dioctyl sodium sulfosuccinate conducted in 1968 showed 12 of 15 older inpatients to be less constipated than when they received placebo before active treatment (mean difference of $1.0 \pm 0.29$ stools $/ \mathrm{wk}, p<0.01) .{ }^{28}$

\section{Prokinetic agents}

Prokinetic agents act by stimulating 5-hydroxytryptamine-4 $\left(5-\mathrm{HT}_{4}\right)$ receptors in the intestine, which induces peristalsis. Two previousgeneration prokinetics, cisapride and tegaserod, were removed from the market because of concerns about cardiac safety. ${ }^{33}$

A newer agent, prucalopride, with less affin- ity for the human ether-à-go-go-related gene (hERG) protein and less anticipated cardiovascular effects than other prokinetic agents, has been tested. Three different doses of prucalopride were evaluated for 4 weeks in 300 older participants. ${ }^{29}$ Only the 4-mg dose, at one time point (wk 1), reached statistical significance for the primary outcome of 3 or more spontaneous and complete bowel movements per week. No differences in adverse effects were observed between the groups.

Concerns about a 9-year delay between the completion of a study evaluating prucalopride in adults with constipation and submission for publication have been raised. ${ }^{33}$ Prucalopride (Resotran) was approved by Health Canada in 2011 for use in women with constipation in whom laxatives have failed. A recommendation for the use of prucalopride in older people cannot be made at this time.

\section{Enemas and suppositories}

We did not find RCTs that evaluated the use of only enemas and suppositories to treat chronic constipation in older people. In one RCT, 206 frail residents in long-term care facilities who had a history of fecal incontinence and impaction were randomly assigned to receive either lactulose alone or lactulose with a daily glycerine suppository and weekly enemas with tap water. ${ }^{34}$ Among the 123 participants remaining in the study after 5 weeks, episodes of incontinence and soiled laundry did not differ significantly between the study arms.

\section{Lifestyle modifications}

Our search did not identify RCTs of fluid intake or physical activity for constipation in older people. A retrospective cohort study involving 883 older volunteers did not find an association between chronic constipation and intake of fewer than 3 glasses, between 3 and 5 glasses, or 6 or more glasses of water per day (odds ratio [OR] $0.847,95 \%$ CI $0.53-1.38) .{ }^{35}$ However, low fluid intake in a cohort of nursing home residents was found to be a risk factor for the development of constipation (OR 1.49, 95\% CI 1.21-1.82). ${ }^{36}$

Physical activity, in the form of resistance and functional-skills training, was evaluated in longterm care facilities but failed to show benefit over the control (a program involving discussions about topics of interest to older people, such as history, music and relaxation). ${ }^{37}$

Appropriate physical activity should be encouraged for other health outcomes and may improve symptoms of constipation, but definitive evidence for improvement in constipation is 
lacking. Promoting fluid intake with the goal of improving symptoms of constipation is not supported by the literature.

\section{Biofeedback}

In dyssynergic defecation, a subtype of chronic constipation, musculature in the pelvic floor, particularly the puborectalis muscle and external anal sphincter, contract inappropriately during defecation, leading to difficulty passing stool and incomplete evacuation. Biofeedback is a method patients can learn to help gain control of relaxing these muscles during defecation. ${ }^{38}$ The availability of biofeedback therapy is low.

A 4-week RCT of electromyographic biofeedback sessions twice weekly, conducted with 30 cognitively intact older people, reported an increase in stool frequency from 2 to 4 bowel movements per week compared with controls who received information on bowel functioning and counselling sessions twice weekly focused on the behavioural mechanisms involved in defecation $(p<0.01) \cdot{ }^{30}$ Constipation was diagnosed based on Rome criteria, and efficacy was maintained up to 2 months after treatment. Adverse effects were not reported in this study.

\section{Comparison with studies involving younger adults}

We did not find reports of direct comparisons between younger and older adults. However, the results from studies presented in our review are similar to those reported in systematic reviews synthesizing data for adults irrespective of age. The American College of Gastroenterology provides a grade A recommendation for the use of polyethylene glycol and lactulose to improve stool frequency and consistency in adults. Psyllium, a bulk agent, received a grade B recommendation for improvement of stool frequency.

Table 1: Characteristics of treatments of chronic constipation in older people

\begin{tabular}{|c|c|c|c|}
\hline Category; mechanism & Treatment & Dose & Adverse effects \\
\hline \multirow{5}{*}{$\begin{array}{l}\text { Osmotic agents } \\
\text { Increase water content in } \\
\text { colon to maintain } \\
\text { isotonicity with plasma }\end{array}$} & Polyethylene glycol & $17-34 \mathrm{~g} / \mathrm{d}$ & $\begin{array}{l}\text { Bloating, flatulence, abdominal pain, } \\
\text { diarrhea }\end{array}$ \\
\hline & Lactulose & $\begin{array}{l}15-30 \mathrm{~mL} \text { daily to twice } \\
\text { daily }\end{array}$ & $\begin{array}{l}\text { Bloating, flatulence, abdominal pain, } \\
\text { diarrhea }\end{array}$ \\
\hline & Sorbitol & $\begin{array}{l}15-30 \mathrm{~mL} \text { daily to twice } \\
\text { daily }\end{array}$ & $\begin{array}{l}\text { Bloating, flatulence, abdominal pain, } \\
\text { diarrhea }\end{array}$ \\
\hline & Magnesium hydroxide & $\begin{array}{l}15-30 \mathrm{mg} \text { daily to twice } \\
\text { daily }\end{array}$ & $\begin{array}{l}\text { Hypermagnesemia, bloating, flatulence, } \\
\text { abdominal pain, diarrhea }\end{array}$ \\
\hline & Sodium phosphate & $\begin{array}{l}10-25 \mathrm{~mL} \text { with } 350 \mathrm{~mL} \\
\text { of water }\end{array}$ & $\begin{array}{l}\text { Hyperphosphatemia, hypocalcemia, } \\
\text { hypernatremia and hypokalemia, bloating, } \\
\text { flatulence, abdominal pain, diarrhea }\end{array}$ \\
\hline \multirow{3}{*}{$\begin{array}{l}\text { Bulk agents } \\
\text { Fibre retains water, which } \\
\text { increases fecal mass, } \\
\text { stimulating peristalsis }\end{array}$} & Psyllium & Up to $20 \mathrm{~g} / \mathrm{d}$ & $\begin{array}{l}\text { Bloating, flatulence; rarely cases of } \\
\text { mechanical obstruction and allergic reactions }\end{array}$ \\
\hline & Methylcellulose & Up to $20 \mathrm{~g} / \mathrm{d}$ & Bloating, flatulence \\
\hline & Polycarbophil & Up to $20 \mathrm{~g} / \mathrm{d}$ & Bloating, flatulence \\
\hline \multirow[t]{2}{*}{$\begin{array}{l}\text { Stimulants } \\
\text { Increase intestinal motility }\end{array}$} & Sennoside & $\begin{array}{l}\text { Up to } 68.8 \mathrm{~g} / \mathrm{d} \text { in } \\
\text { divided doses }\end{array}$ & $\begin{array}{l}\text { Abdominal cramps, hypokalemia, } \\
\text { pseudomelanosis coli }\end{array}$ \\
\hline & Bisacodyl & $\begin{array}{l}5-10 \mathrm{mg} / \mathrm{d} \text { orally or } \\
\text { rectally }\end{array}$ & $\begin{array}{l}\text { Abdominal cramps, hypokalemia, } \\
\text { pseudomelanosis coli }\end{array}$ \\
\hline \multirow{2}{*}{$\begin{array}{l}\text { Stool softeners } \\
\text { Decrease stool surface } \\
\text { tension leading to increased } \\
\text { water penetration }\end{array}$} & $\begin{array}{l}\text { Dioctyl sodium } \\
\text { sulfosuccinate or docusate }\end{array}$ & 100 mg twice daily & Abdominal cramps, diarrhea \\
\hline & Docusate calcium & 240 mg twice daily & Abdominal cramps, diarrhea \\
\hline $\begin{array}{l}\text { Prokinetic agents } \\
\text { Stimulates } 5-\mathrm{HT}_{4} \text { intestinal } \\
\text { receptors, inducing peristalsis }\end{array}$ & Prucalopride & $2 \mathrm{mg} / \mathrm{d}$ & Nausea, vomiting, flatulence, headache \\
\hline \multirow{3}{*}{$\begin{array}{l}\text { Enemas or suppositories } \\
\text { Enemas distend the rectum } \\
\text { to initiate the defecation } \\
\text { reflex; they also soften stool }\end{array}$} & Phosphate-based enema & $120 \mathrm{~mL} / \mathrm{d}$ & $\begin{array}{l}\text { Hyperphosphatemia and other electrolyte } \\
\text { disturbances }\end{array}$ \\
\hline & Tap-water enema & $500 \mathrm{~mL} / \mathrm{d}$ & \\
\hline & Glycerin suppository & Once daily & \\
\hline
\end{tabular}


Data were insufficient to recommend the use of other bulk agents, magnesium hydroxide, stool softeners and stimulants. ${ }^{39}$

\section{Are there new pharmacotherapeutic options?}

Pharmacotherapies targeted at specific cellular receptors in the gastrointestinal tract have been developed and studied in adults. To date, they have not been approved for use in Canada.

Since 2006, lubiprostone has been approved for use in the United States. Lubiprostone acti- vates type 2 chloride channels, enhancing the secretion of chloride-rich intestinal fluid. A meta-analysis of data from 3 RCTs $(n=610)$ comparing this medication with placebo in adults revealed a benefit in spontaneous bowel movements (risk ratio [RR] of failure to respond to therapy $0.67,95 \%$ CI $0.56-0.80)$. $^{40}$ (Two of the trials reported the proportion of participants aged 65 years or older [10\% and $13.2 \%$ ].) Diarrhea (RR 4.46, 95\% CI 1.28-15.48) and nausea (RR 7.27, 95\% CI 3.76-14.06) were more frequent with lubiprostone than with placebo. ${ }^{40}$ Self-limited shortness of breath following the first dose has also been observed. ${ }^{41}$

Table 2: Stepwise approach to the management of constipation in older people

\begin{tabular}{|c|c|}
\hline Step & Details \\
\hline $\begin{array}{l}\text { 1. Identify the predominant } \\
\text { symptom* }\end{array}$ & Frequency, straining, incomplete evacuation \\
\hline $\begin{array}{l}\text { 2. Identify possible secondary } \\
\text { causes of constipation* }\end{array}$ & $\begin{array}{l}\text { - Medications (e.g., opioids, nondihydropyridine calcium-channel } \\
\text { blockers, iron supplements and antidiarrheal agents) } \\
\text { - Disease states (e.g., colon cancer, stroke and Parkinson disease) } \\
\text { - Secondary causes of constipation are treated in the same } \\
\text { manner as primary constipation } \\
\text { - If alarm symptoms or signs are present (see Box 5), local or } \\
\text { national guidelines for colon cancer screening should be } \\
\text { followed }\end{array}$ \\
\hline 3. Exclude fecal impaction* & $\begin{array}{l}\text { - In a person who is bedbound or has severe dementia, an } \\
\text { abdominal radiograph or a digital rectal examination } \neq \text { can be } \\
\text { used to diagnose impaction } \\
\text { - Manual disimpaction is often necessary to treat fecal impaction }\end{array}$ \\
\hline 4. Optimize behavioural factorst & $\begin{array}{l}\text { - The seated position, with knees at or above the level of hips, } \\
\text { is advised } \\
\text { - If the person has moderate to severe cognitive impairment, } \\
\text { allow adequate time to toilet after the morning meal, to take } \\
\text { advantage of the gastrocolic reflex }\end{array}$ \\
\hline $\begin{array}{l}\text { 5. Trial of dietary modifications } \\
(2-4 \mathrm{wk})\end{array}$ & $\begin{array}{l}\text { - Gradually increase fibre intake to } 20-30 \mathrm{~g} / \mathrm{d} \text { from dietary (fruits, } \\
\text { vegetables, legumes) or supplemental sources (psyllium, } \\
\text { methylcellulose, calcium polycarbophil) } \\
\text { - Not advised in a person who is immobile or bedbound, to avoid } \\
\text { impaction or obstruction }\end{array}$ \\
\hline $\begin{array}{l}\text { 6. Trial of a previously preferred } \\
\text { laxative agent ( } 2-4 \mathrm{wk})\end{array}$ & $\begin{array}{l}\text { - The patient may prefer one agent over another from past } \\
\text { experience }\end{array}$ \\
\hline $\begin{array}{l}\text { 7. Trial of a laxative agent } \\
\text { supported by evidence from } \\
\text { RCTs involving older people } \\
\text { ( } 2-4 \text { wk) }\end{array}$ & $\begin{array}{l}\text { - Polyethylene glycol } 17-34 \mathrm{~g} / \mathrm{d} \\
\text { - Lactulose } 15-30 \mathrm{~mL} \text { daily to twice daily }\end{array}$ \\
\hline $\begin{array}{l}\text { 8. Trial of another laxative agent } \\
\text { or a combination of agents } \\
\text { from different classes ( } 2-4 \mathrm{wk})\end{array}$ & $\begin{array}{l}\text { - Magnesium hydroxide } 15-30 \text { mg daily to twice daily } \\
\text { - Docusate calcium } 240 \mathrm{mg} \text { twice daily } \S \\
\text { - Bisacodyl 5-10 } \mathrm{mg} / \mathrm{d} \text { orally or rectally } \\
\text { - Sennoside, up to } 68.8 \mathrm{~g} / \mathrm{d} \text { in divided doses } \\
\text { - Enema or suppository }\end{array}$ \\
\hline \multicolumn{2}{|l|}{$\begin{array}{l}\text { 9. Referral to a gastroenterologist } \\
\text { or geriatrician }\end{array}$} \\
\hline \multicolumn{2}{|c|}{$\begin{array}{l}\text { Note: RCT = randomized controlled trial. } \\
\text { *Steps } 1 \text { through } 3 \text { should be undertaken concurrently. } \\
\text { †Step } 4 \text { should be undertaken concurrently with each of steps } 5 \text { through } 8 \text {. } \\
\text { †A negative digital rectal examination does not exclude the possibility of impaction more proximally. If the suspicion is high, an } \\
\text { abdominal radiograph should be obtained. } \\
\text { §Docusate calcium and docusate sodium are generally considered to be mild laxatives. }\end{array}$} \\
\hline
\end{tabular}


Linaclotide is a minimally absorbed, 14amino-acid peptide that binds to the guanylate cyclase $\mathrm{C}$ receptor on the luminal surface of intestinal enterocytes. Binding initiates a signal transduction cascade that activates the cystic fibrosis transmembrane conductance regulator. This action promotes the release of chloride and bicarbonate into the intestinal lumen, thereby increasing colonic secretion and intestinal motility. In a systematic review and meta-analysis, 3 RCTs ( $n=1582)$ comparing linaclotide with placebo in adults revealed a greater response to linaclotide than to placebo (RR of failure to respond to therapy $0.84,95 \%$ CI $0.80-0.87) .^{40}$ Diarrhea was more common in the treatment group than in the placebo group (RR 3.08, 95\% CI 1.27-7.48). ${ }^{40}$ Linaclotide is not approved for use in Canada.

\section{How can this review be applied in practice?}

Constipation is usually manageable without extensive investigation, and most therapies carry a low risk of adverse events (Table 1). ${ }^{42}$ Behavioural measures to increase the chance of treatment success include ensuring adequate time to toilet, positioning the knees at or above the level of the hips for mechanical advantage while defecating, and taking advantage of the gastrocolic reflex by guiding cognitively impaired individuals to toilet following a meal. Based on our review of the literature and clinical experience, a stepwise approach is presented in Table 2.

\section{Gaps in knowledge}

Our review highlights some deficiencies in the research on constipation in older people. First, the overall reported quality of the trials retrieved in our search was low. The mean quality score according to the Jadad scale ${ }^{43}$ was 2.6 out of a possible 5 points. Only 3 trials ${ }^{18,26,29}$ scored 4 or greater, which is generally considered high quality. Common sources of bias included inadequately described processes for randomization and concealment of allocation, lack of blinding and variable follow-up. Confidence intervals surrounding point estimates were not always reported, and outcome measures were inconsistent across trials, with some reporting spontaneous bowel movements and others using composite outcomes. These studies are therefore at high risk of bias. However, the results from studies assessing osmotic laxatives were consistent with welldesigned studies involving younger adults ${ }^{4,45}$ and can be used to guide treatment decisions.
Second, the baseline definition of constipation varied extensively between trials, and most studies did not adhere to a standardized definition such as the Rome criteria for inclusion of participants. The trial by Zangaglia and colleagues ${ }^{18}$ of polyethylene glycol in patients with Parkinson disease and the trial by Simón and Bueno ${ }^{30}$ of electromyography biofeedback are the exceptions.

Third, laxatives were not assessed in specific subtypes of chronic constipation. As with most geriatric syndromes, however, a single isolated pathology accounting for symptoms is less common than multiple contributing factors.

\section{Conclusion}

Constipation is highly prevalent in older people. It can be the result of multiple contributing factors such as medication use and underlying disease states as well as primary constipation. The symptoms can have a profound impact on quality of life and in certain circumstances may lead to functional decline. Physicians should educate their patients on the wide range of normal bowel habits and the potential benefits of dietary modifications to improve symptoms. RCTs involving older participants have revealed the benefits of osmotic laxatives, such as polyethylene glycol and lactulose. Evidence supporting the use of bulk agents, stool softeners, stimulants and prokinetic agents was lacking, limited or inconsistent.

\section{References}

1. Higgins PD, Johanson JF. Epidemiology of constipation in North America: a systematic review. Am J Gastroenterol 2004;99:750-9.

2. Campbell AJ, Busby WJ, Horwath CC. Factors associated with constipation in a community based sample of people aged 70 years and over. J Epidemiol Community Health 1993;47:23-6.

3. Kinnunen O. Study of constipation in a geriatric hospital, day hospital, old people's home and at home. Aging (Milano) 1991;3: 161-70.

4. Towers AL, Burgio KL, Locher JL, et al. Constipation in the elderly: influence of dietary, psychological, and physiological factors. J Am Geriatr Soc 1994;42:701-6.

5. Stewart RB, Moore MT, Marks RG, et al. Correlates of constipation in an ambulatory elderly population. Am J Gastroenterol 1992;87:859-64.

6. Young RW. The problem of fecal impaction in the aged. $J$ Am Geriatr Soc 1973;21:383.

7. Wrenn K. Fecal impaction. N Engl J Med 1989;321:658-62.

8. Ouaïssi M, Sielezneff I, Benoist S, et al. Lethal fecaloma. $J$ Am Geriatr Soc 2007;55:965-7.

9. Frank L, Schmier J, Kleinman L, et al. Time and economic cost of constipation care in nursing homes. J Am Med Dir Assoc 2002;3:215-23

10. Harari D, Gurwitz JH, Avorn J, et al. How do older persons define constipation? Implications for therapeutic management. J Gen Intern Med 1997;12:63-6.

11. Ashraf W, Park F, Lof J, et al. An examination of the reliability of reported stool frequency in the diagnosis of idiopathic constipation. Am J Gastroenterol 1996;91:26-32.

12. Rome III diagnostic criteria for functional gastrointestinal disorders. Raleigh (NC): Rome Foundation; 2006. Available: www.romecriteria.org/assets/pdf/19_RomeIII_apA_885-898.pdf (accessed 2012 Dec. 7).

13. Camilleri M, Lee JS, Viramontes B, et al. Insights into the pathophysiology and mechanisms of constipation, irritable bowel syndrome, and diverticulosis in older people. J Am Geriatr Soc 2000;48:1142-50. 
14. Gallagher P, O'Mahony D. Constipation in old age. Best Pract Res Clin Gastroenterol 2009;23:875-87.

15. Sanders JF. Lactulose syrup assessed in a double-blind study of elderly constipated patients. J Am Geriatr Soc 1978;26:236-9.

16. Vanderdonckt J, Coulon J, Denys W, et al. Study of the laxative effect of lactitol (Importal) in an elderly institutionalized, but not bedridden, population suffering from chronic constipation. J Clinical and Exp Gerontol 1990;21:171-89.

17. Wesselius-De Casparis A, Braadbaart S, Bergh-Bohlken GE, et al. Treatment of chronic constipation with lactulose syrup: results of a double-blind study. Gut 1968;9:84-6.

18. Zangaglia R, Martignoni E, Glorioso M, et al. Macrogol for the treatment of constipation in Parkinson's disease. A randomized placebo-controlled study. Mov Disord 2007;22:1239-44.

19. Cheskin LJ, Kamal N, Crowell MD, et al. Mechanisms of constipation in older persons and effects of fiber compared with placebo. J Am Geriatr Soc 1995;43:666-9.

20. Ewerth S, Ahlberg J, Holmstrom B, et al. Influence on symptoms and transit-time of Vi-SiblinR in diverticular disease. Acto Chir Scand Suppl 1980;500:49-50.

21. Rajala SA, Salminen SJ, Seppanen JH, et al. Treatment of chronic constipation with lactitol sweetened yoghurt supplemented with guar gum and wheat bran in elderly hospital inpatients. Compr Gerontol [A] 1988;2:83-6.

22. Sairanen U, Piirainen L, Nevala R, et al. Yoghurt containing galacto-oligosaccharides, prunes and linseed reduces the severity of mild constipation in elderly subjects. Eur J Clin Nutr 2007; 61:1423-8

23. Snustad D, Lee V, Abraham I, et al. Dietary fiber in hospitalized geriatric patients: Too soft a solution for too hard a problem? J Nutr Elder 1991;10(2):49-63.

24. Teuri U, Korpela R. Galacto-oligosaccharides relieve constipation in elderly people. Ann Nutr Metab 1998;42:319-27.

25. Surakka A, Kajander K, Rajilic-Stojanovic M. Yoghurt containing galactooligosaccharides facilitates defecation among elderly subjects and selectively increases the number of bifidobacteria. Int J Probiotics Prebiotics 2009;4:65-74

26. Bub S, Brinckmann J, Cicconetti G, et al. Efficacy of an herbal dietary supplement (Smooth Move) in the management of constipation in nursing home residents: a randomized, doubleblind, placebo-controlled study. J Am Med Dir Assoc 2006;7: 556-61.

27. Huang $\mathrm{C}, \mathrm{Su} \mathrm{Y,} \mathrm{Li} \mathrm{T,} \mathrm{et} \mathrm{al.} \mathrm{Treatment} \mathrm{of} \mathrm{constipation} \mathrm{in} \mathrm{long-}$ term care with Chinese herbal formula: a randomized, doubleblind placebo-controlled trial. J Altern Complement Med 2011; 17:639-46.

28. Hyland CM, Foran JD. Dioctyl sodium sulphosuccinate as a laxative in the elderly. Practitioner 1968;200:698-9.

29. Müller-Lissner S, Rykx A, Kerstens R, et al. A double-blind, placebo-controlled study of prucalopride in elderly patients with chronic constipation. Neurogastroenterol Motil 2010;22:991-8.

30. Simón MA, Bueno AM. Behavioural treatment of the dyssynergic defecation in chronically constipated elderly patients: a randomized controlled trial. Appl Psychophysiol Biofeedback 2009; 34:273-7.

31. Xing JH, Soffer EE. Adverse effects of laxatives. Dis Colon Rectum 2001;44:1201-9.

32. Pérez-Piqueras J, Silva C, Jaqueti J. Endoscopic diagnosis and treatment of an esophageal bezoar resulting from bulk laxative ingestion. Endoscopy 1994;26:710.
33. Moss AJ. The long and short of a constipation-reducing medication. N Engl J Med 2008;358:2402-3.

34. Chassagne P, Jego A, Gloc P, et al. Does treatment of constipation improve faecal incontinence in institutionalized elderly patients? Age Ageing 2000;29:159-64.

35. Lindeman RD, Romero LJ, Liang HC, et al. Do elderly persons need to be encouraged to drink more fluids? J Gerontol A Biol Sci Med Sci 2000;55:M361-5

36. Robson KM, Kiely DK, Lembo T. Development of constipation in nursing home residents. Dis Colon Rectum 2000;43:940-3.

37. Chin A Paw MJ, van Poppel MN, van Mechelen W. Effects of resistance and functional-skills training on habitual activity and constipation among older adults living in long-term care facilities: a randomized controlled trial. BMC Geriatr 2006;6:9.

38. Bassotti G, Chistolini F, Sietchiping-Nzepa F, et al. Biofeedback for pelvic floor dysfunction in constipation. BMJ 2004:328:393-6.

39. Brandt LJ, Prather CM, Quigley EM, et al. Systematic review on the management of chronic constipation in North America. Am J Gastroenterol 2005;100(Suppl 1):S5-21.

40. Ford AC, Suares NC. Effect of laxatives and pharmacological therapies in chronic idiopathic constipation: systematic review and meta-analysis. Gut 2011;60:209-18.

41. Lacy BE, Chey WD. Lubiprostone: chronic constipation and irritable bowel syndrome with constipation. Expert Opin Pharmacother 2009; 10:143-52

42. Lembo A, Camilleri M. Chronic constipation. $N$ Engl J Med 2003:349:1360-8

43. Jadad AR, Moore RA, Carroll D, et al. Assessing the quality of reports of randomized clinical trials: Is blinding necessary? Control Clin Trials 1996;17:1-12.

44. Corazziari E, Badiali D, Bazzocchi G, et al. Long term efficacy, safety, and tolerabilitity of low daily doses of isosmotic polyethylene glycol electrolyte balanced solution (PMF-100) in the treatment of functional chronic constipation. Gut 2000;46:522-6.

45. Attar A, Lemann M, Ferguson A, et al. Comparison of a low dose polyethylene glycol electrolyte solution with lactulose for treatment of chronic constipation. Gut 1999;44:226-30.

Affiliations: From the Department of Medicine (Gandell), Sunnybrook Health Sciences Centre; the Department of Medicine (Straus), University of Toronto; the Department of Medicine (Bundookwala), University Health Network; the Department of Medicine (Tsui), St. Joseph's Health Centre; and the University Health Network (Alibhai), Toronto, Ont.

Contributors: Dov Gandell was responsible for the conception and design of the article, the acquisition of data, the analysis and interpretation of data and the drafting of the article. Sharon Straus assisted with the conception and design of the article, and the analysis and interpretation of data. Maria Bundookwala and Vincent Tsui were responsible for duplicating the search for articles and the data extraction. Shabbir Alibhai supervised the conception and design of the literature search and assisted with the acquisition of data, and the analysis and interpretation of data. All of the authors contributed to the revising of the manuscript and approved the final version submitted for publication.

\section{Call for papers: CMAJ Holiday Reading}

'Twas months before the holidays and all through CMAJ house not a submission was stirring, making editors grouse. "Holiday Reading time is nigh!" they cried in despair, in hopes that your papers soon would be there.

Submit your evidence-based research on quirky topics, brilliant missives or holiday-themed visuals at http://mc.manuscriptcentral.com/cmaj. Submissions should be no longer than 1200 words. For information contact kelly.clarke@cma.ca

Deadline: October 1, 2013

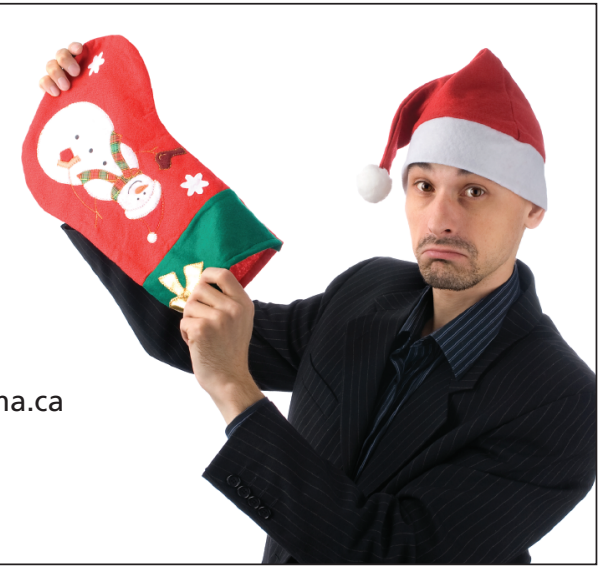

